\title{
Phycosynthesis of silver nanoparticles and photocatalytic degradation of methyl orange dye using silver (Ag) nanoparticles synthesized from Hypnea musciformis (Wulfen) J.V. Lamouroux
}

\author{
G. Ganapathy Selvam • K. Sivakumar
}

Received: 15 June 2014/ Accepted: 28 August 2014/Published online: 16 September 2014

(C) The Author(s) 2014. This article is published with open access at Springerlink.com

\begin{abstract}
In the present investigation, simple and ecofriendly chemical reaction for the synthesis reported on biological synthesis of nano-sized silver and biosynthesis of silver nanoparticles using Hypnea musciformis at room temperature along with photocatalytic degradation of methyl orange dye. The nanoparticles of silver were formed by the reduction of silver nitrate to aqueous silver metal ions during exposure to the extract of red alga H. musciformis. The optical properties of the obtained silver nanoparticles were characterized by applying UVvisible absorption and room temperature photoluminescence. The X-ray diffraction results revealed that the synthesized silver nanoparticles were in the cubic phase. The existence of functional groups was identified using Fourier transform infrared spectroscopy. The morphology and size of the synthesized particles were studied with atomic force microscope measurements. Photocatalytic degradation of methyl orange was measured spectrophotometrically by using silver as nanocatalyst under visible light illumination. The results revealed that biosynthesized silver nanoparticles using $H$. musciformis was found to be impressive in degrading methyl orange.
\end{abstract}

Keywords Hypnea musciformis - Cubical phase - Silver nanoparticles · XRD · FT-IR · AFM - Photocatalytic degradation

G. Ganapathy Selvam · K. Sivakumar $(\bowtie)$

Division of Algal Biotechnology, Department of Botany,

Annamalai University, Annamalainagar, Chidambaram 608 002,

Tamil Nadu, India

e-mail: kshivam69@gmail.com

\section{Introduction}

The field of nanotechnology is one of the most active areas of research in modern materials science. Nanoparticles exhibit completely new or improved properties based on specific characteristics such as size, distribution and morphology. New applications of nanoparticles and nanomaterials are emerging rapidly (Murphy 2008). It is believed that nanoparticles are clusters of atoms in the size range of 1-100 nm (Williams 2008). Nanoparticles are classified primarily into two types, viz., organic and inorganic nanoparticles.

The nanoparticles of carbon are called the organic nanoparticles. Magnetic nanoparticles, noble metal nanoparticles (platinum, gold and silver) and semiconductor nanoparticles (titanium dioxide, zinc oxide and zinc sulfide) are classified as inorganic nanoparticles (Kathiresan and Asmathunisha 2013). The metal nanoparticles have magnetic, electronic and optical properties, which make their usage in different fields like medicine, agriculture and electronics (Rai et al. 2012). Nanoparticles of silver are widely used in water filters (Jain and Pradeep 2005) and biosensors (Chen et al. 2007).

Dyes belong to the class of synthetic organic compounds and are widely used in the textile industry. The removal of these non-biodegradable organic chemicals from the environment is a crucial ecological problem. Many techniques, such as activated carbon sorption, flocculation, electrocoagulation, UV-light degradation and redox treatments, are being routinely used for abating dyes (Kumar et al. 2011). However, due to the ineffectiveness of these techniques in some way or the other, the present scenario requires better and improved wastewater treatment measures. Recently, metal nanoparticles were reported as effective photocatalysts for degrading chemical complexes, under ambient temperature with visible light illumination (Mohamed et al. 2012). This can be achieved by increasing 
the optical path of photons leading to a higher absorption rate of nanoparticles in the presence of a local electrical field (Garcia 2012). These nanoparticles showed new and improved properties based on their morphological structures and characteristics as compared to bulk materials (Gurunathan et al. 2009). Wang et al. (2008) stated that, Ag nanoparticles are good, highly efficient and stable photocatalysts under ambient temperature with visible light illumination for degrading organic compounds and dyes. Moreover, scientists have also shown considerable interest in using nanoparticles for the photocatalytic degradation of dyes. Of all marine plants, seaweed-mediated biosynthesis of $\mathrm{Ag}$ nanoparticles have been found to be efficient, cost effective and environmental friendly (Kumar et al. 2012a, b). The biosynthetic method employing marine seaweed extract has received more attention as being simple, ecofriendly and less time-consuming compared to usual chemical and physical methods.

The purpose of present study was extracellular synthesis and photocatalytic degradation of methyl orange using silver nanoparticles synthesized from Hypnea musciformis.

\section{Materials and methods}

Synthesis of Ag nanoparticles

The red alga $H$. musciformis were collected from pudumadam coastal region $\left(9.27^{\circ} \mathrm{N}, 78.99^{\circ} \mathrm{E}\right)$ in Gulf of mannar, southeast coast of India. Immediately after the collection, the samples were transferred to the laboratory in new plastic bags containing natural sea water to prevent desiccation. Voucher specimen of the H. musciformis (Accession no. 252) was deposited in a Herbarium in Department of Botany, Annamalai University. Further, the seaweed was cleaned with distilled water and shade dried for 15 days (Kumar et al. 2012a, b). Fine powder of the seaweed was obtained by using kitchen blender. The seaweed powder was sterilized at $120^{\circ} \mathrm{C}$ for $15 \mathrm{~min}, 20 \mathrm{~g}$ of powder was taken and mixed with $100 \mathrm{ml}$ of milli-Q water and kept in boiling water bath at $60{ }^{\circ} \mathrm{C}$ for $20 \mathrm{~min}$. The extract was filtered with Whatman No. 1 filter paper and stored in a refrigerator at $4{ }^{\circ} \mathrm{C}$ for further studies. For the biosynthesis of silver nanoparticles, $5 \mathrm{ml}$ of alga extract was mixed with $50 \mathrm{ml}$ of $\mathrm{AgNO}_{3}$ solution and incubated at $28^{\circ} \mathrm{C}$ for $24 \mathrm{~h}$. The bio-reduction of $\mathrm{AgNO}_{3}$ into AgNPs can be confirmed visually by the change in color from watery to reddish brown (Fig. 1).

\section{Characterization techniques}

Characterization of nanoparticles is important to understand and control nanoparticle synthesis and applications

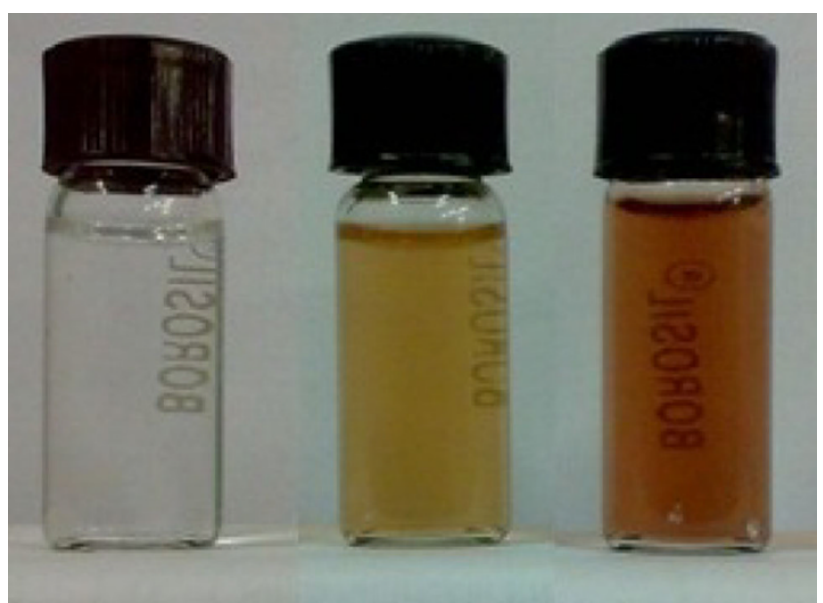

Fig. 1 The aqueous extract of $H$. musciformis before and after synthesis of AgNPs

(Al-Warthan et al. 2010). The formation of AgNPs was confirmed by sampling the reaction mixture at regular intervals, and the maximum absorption was scanned by UV-visible spectra, in a range of wavelength between 400 and $550 \mathrm{~nm}$ using (Shimadzu, UV-2450, Japan) spectrometer.

The presence of functional groups in seaweed extract and synthesized AgNPs was identified by SHIMADZU8400 FTIR Spectrometer using $\mathrm{KBr}$ pellet technique.

The X-ray diffraction (XRD) patterns of the silver nanoparticles were recorded using X'PERT PRO diffractometer with $\mathrm{Cu}-\mathrm{Ka}$ radiation $(k=1.5406 \AA)$. The crystallite size was estimated using the Scherer equation. Fluorescence measurements of the synthesized products with different incubation time were carried out using VARIAN Spectrometer.

Scanning electron microscopic (SEM) analysis was done using JOEL JSM-56010 with INSA-EDS machine. Thin films of the sample were prepared on a gold coated copper grid by just dropping a very small amount of the sample on the grid, extra solution was removed using a blotting paper and then the film on the SEM grid were allowed to dry by putting it under a mercury lamp for 5 min.

The silver nanoparticles extracted were visualized with an atomic force microscope. A thin film of the samples prepared on a glass slides were allowed to dry for $5 \mathrm{~min}$ and then scanned with the AFM.

\section{Photocatalytic degradation}

The photocatalytic degradation of methyl orange was evaluated by biosynthesized $\mathrm{Ag}$ nanoparticles (Rashed and El-Amin 2007). All the experiments were performed outdoor with sun as the main source of light (Wang et al. 


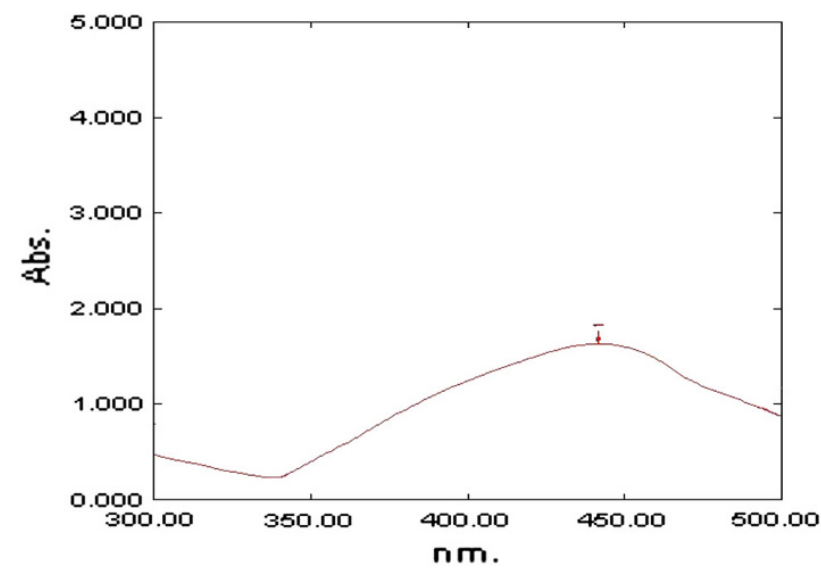

Fig. 2 UV-visible absorption spectrum of silver nanoparticles after 30 min of incubation

2000). Prior to the experiment, a suspension was prepared by adding $20 \mathrm{mg}$ of $\mathrm{Ag}$ nanoparticles to $50 \mathrm{ml}$ of methyl orange solution (Fisher Scientific). Later, the mixture was allowed to stir constantly for about $30 \mathrm{~min}$ in darkness to ensure constant equilibrium of $\mathrm{Ag}$ nanoparticles in the organic solution. During the reaction, the mixture was kept under sunlight within a Pyrex glass beaker and stirred constantly. The mean temperature was found to be $29{ }^{\circ} \mathrm{C}$ with $10 \mathrm{~h}$ mean shine duration. The absorption spectrum of the suspension mixture was measured periodically using a
UV-visible spectrophotometer (Shimadzu, UV-2450, Japan) after centrifugation to ensure the degradation of methyl orange solution.

\section{Results and discussion}

UV-visible spectroscopy

UV-visible spectroscopy is a convenient, preliminary and indirect method for characterization of $\mathrm{Ag}$ nanoparticles based on optical properties called surface plasmon resonance (SPR) (Kannan et al. 2013).

The silver NPs bands occur at $440 \mathrm{~nm}$ with progressive increase in absorbance upon increasing time until $20 \mathrm{~min}$ as shown in Fig. 2. The observed band in this range has been associated with Ag nanoparticles confirming the synthesis of spherical Ag nanoparticles with narrow size distribution.

\section{FTIR spectrum}

FTIR measurements were carried out to identify the possible biomolecules responsible for the reduction of $\mathrm{Ag}^{+}$ ions and the capping of the bioreduced AgNPs synthesized. FTIR spectrum shows (Fig. 3) different major peaks positioned at 3,405.61, 2,958.50, 2,922.09, 2,851.91, 1,639.40,

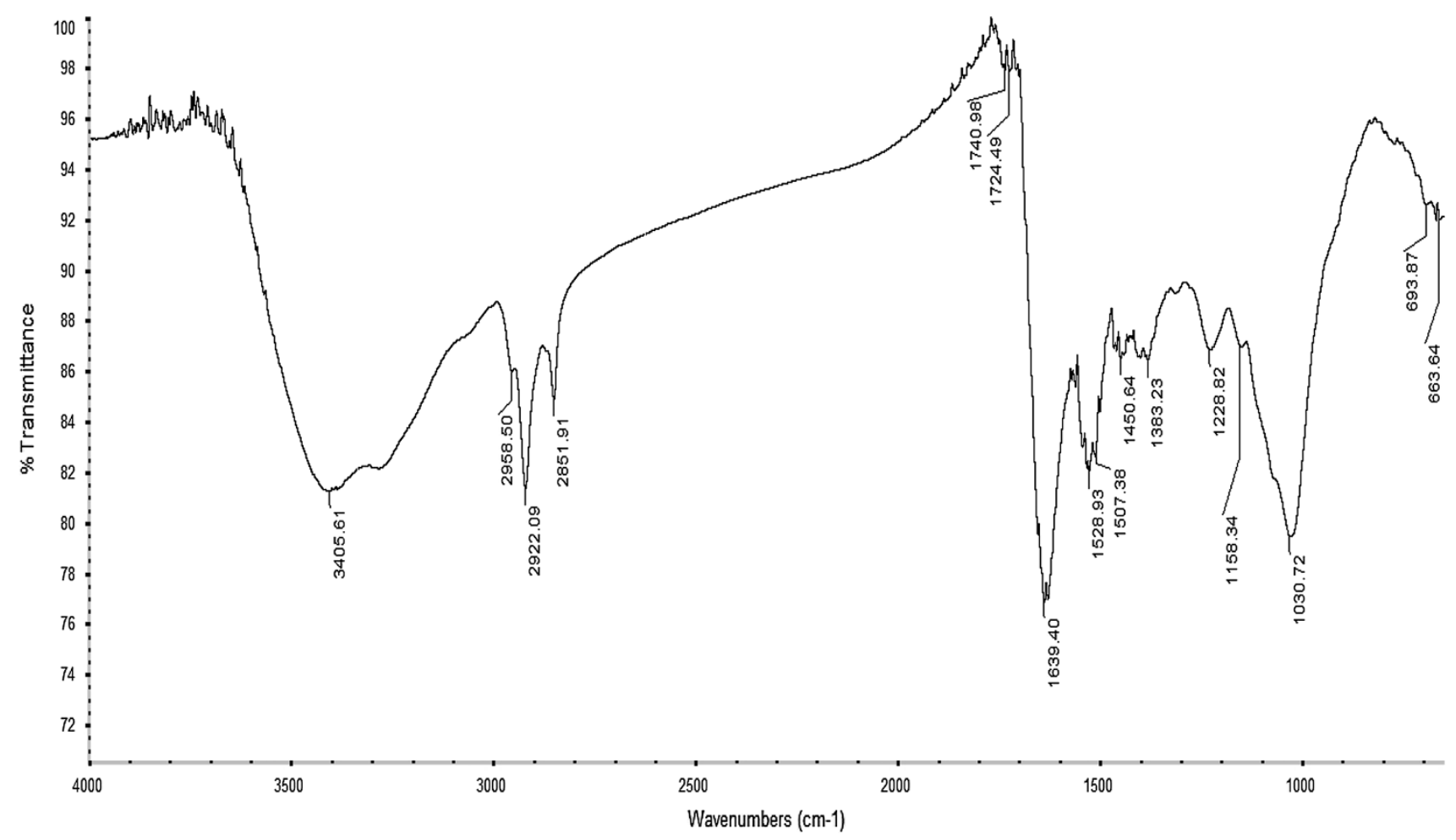

Fig. 3 FTIR spectrum of AgNPs by the extract of H. musciformis 


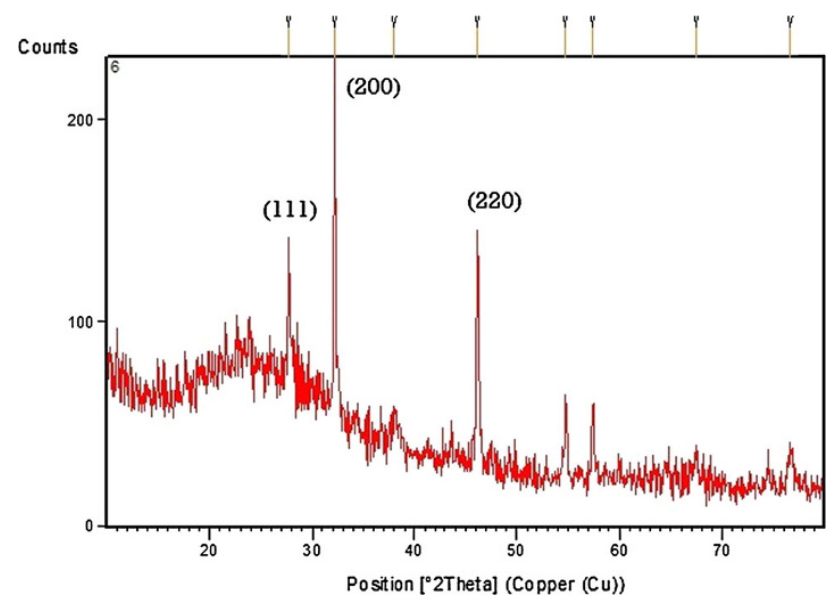

Fig. 4 XRD patterns of silver nanoparticles synthesized after $120 \mathrm{~h}$ of incubation

1,528.93, 1,228.82, 1,030.72, 693.87 and $663.64 \mathrm{~cm}^{-1}$. The presence of peak at $3,405.61 \mathrm{~cm}^{-1}$ could be due to $\mathrm{O}-$ $\mathrm{H}$ group in alcohols and phenols. A peak observed at $2,958.50$ and $2,922.09 \mathrm{~cm}^{-1}$ is due to $\mathrm{C}-\mathrm{H}$ stretching of alkanes amide 1 band of proteins. A sharp and intense band observed at $1,639.40 \mathrm{~cm}^{-1}$ may be recognized to the $\mathrm{N}-\mathrm{H}$ band of primary amines. The bands positioned at 1,228.82, $1,158.34,1,030.72 \mathrm{~cm}^{-1}$ are due to $\mathrm{C}-\mathrm{N}$ stretching vibration of aliphatic amines. The observed bands ranged between 693.87 and $693.64 \mathrm{~cm}^{-1}$ are due to $\mathrm{C}-\mathrm{H}$ band of alkene. After bio-reduction, there is a shift in the absorption band of 139.40, 1,528.93, 1,507.38 $\mathrm{cm}^{-1}$, maybe due to the binding of $(\mathrm{NH}) \mathrm{C}=\mathrm{O}$ group with the nanoparticles. The $(\mathrm{NH}) \mathrm{C}=\mathrm{O}$ groups within the cage of cyclic peptides are involved in stabilizing the nanoparticles. Thus, the peptides may play an important role in the reduction of $\mathrm{Ag}$ nanoparticles. The above-mentioned shift was observed in Codium capitatum (Yang et al. 2012). Several species of Gracilaria have been reported to contain abundant of amino acids, fatty acids, vitamins, minerals, phenolic compounds and carbohydrates (Satyavani et al. 2011). Satyavani et al. have reported that silver ions may possibly bind to phenolic compounds with one or more aromatic ring resulting in the formation of $\mathrm{Ag}$ nanoparticles (Kansal et al. 2006).

Crystal structure analysis and determination of crystallite size

The biosynthesized silver nanoparticles by using $H$. musciformis extracts as shown in the figure (Fig. 4). The pattern has three main diffraction features corresponding to (111), (200) and (220) planes and all the three peaks can be indexed to standard cubic phase of silver (JCPDS card No. 870598,870720 and 893722). No reflection peaks corresponding to nitrate ions and other impurities were noted in this pattern, indicating the high purity of the final product. The different peak intensity profile was characteristic of cubic structure of AgNPs. The size of the particle can be calculated by using Scherrer formula $D=0.9 \lambda / \beta \cos \theta$, where $D$ is the crystalline size, $\lambda$ is the wavelength of $x$-ray
Fig. 5 a SEM micrograph of Silver nanoparticles synthesized from the extracts of H. musciformis and $\mathbf{b}$ energy dispersive spectrometer analysis
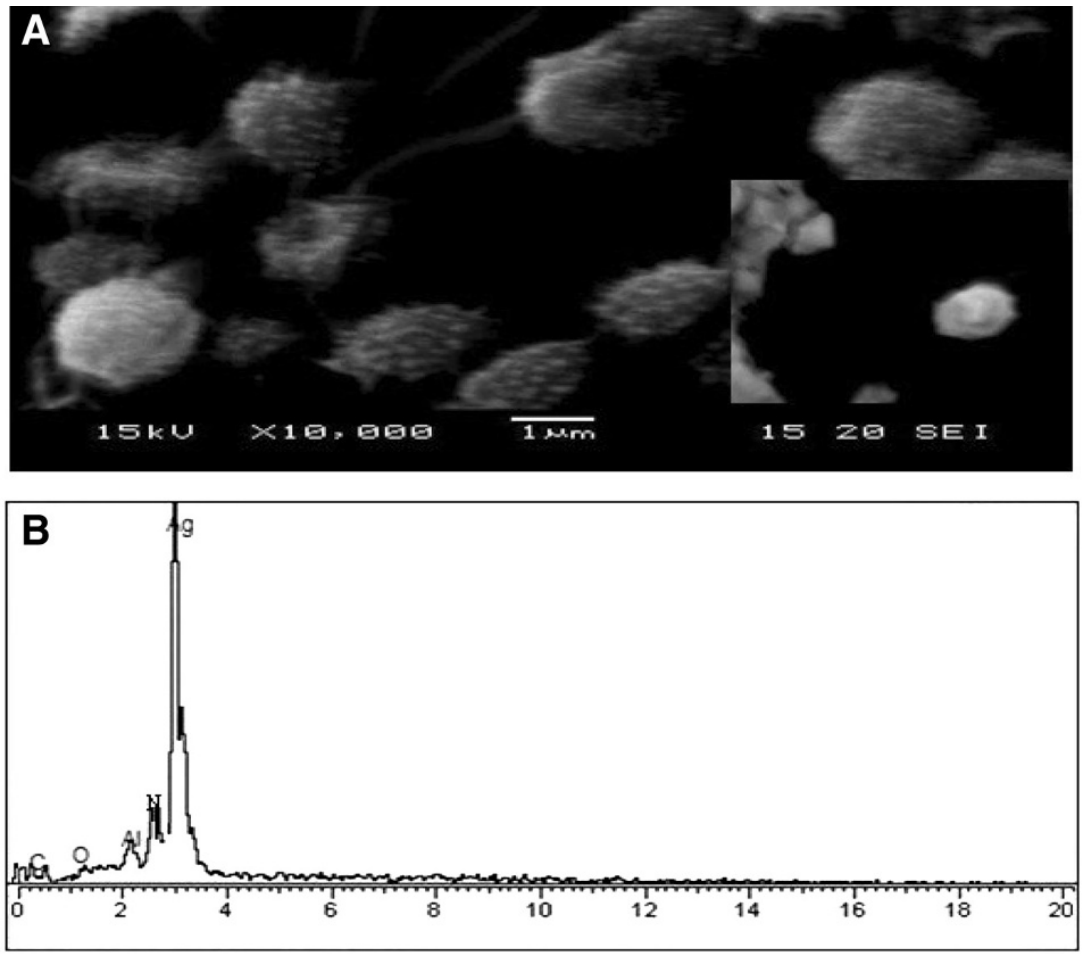

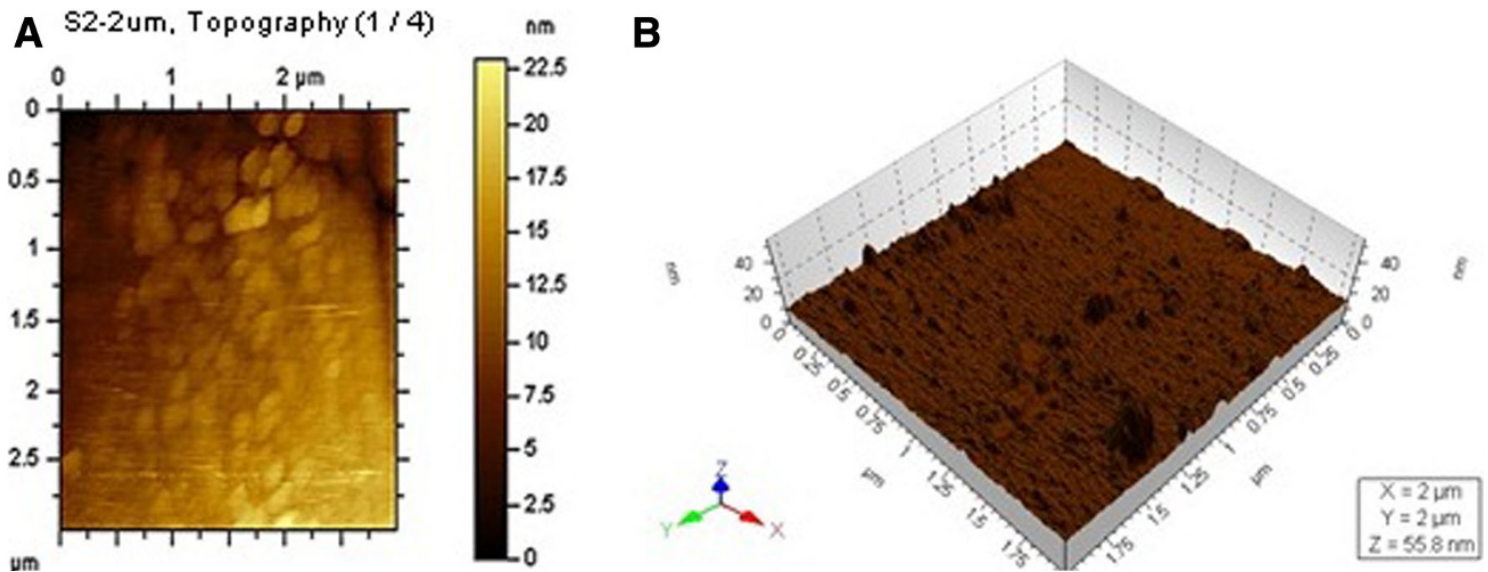

Fig. 6 a AFM images of synthesized silver nanoparticles using extract of Hypnea musciformis and b corresponding 3D view

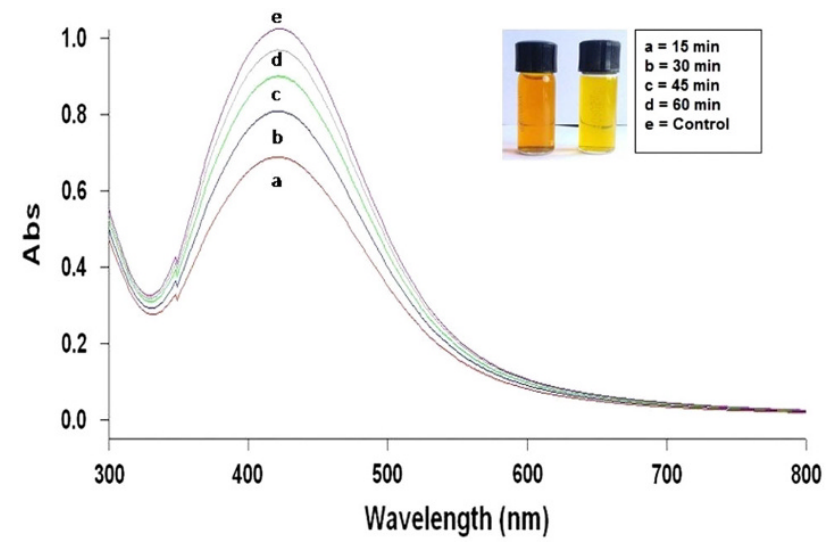

Fig. 7 Photocatalytic degradation of methyl orange using silver nanoparticles synthesized from Hypnea musciformis

used, $\beta$ is the full width at half maximum light of the maximum intensity peak and $\theta$ is the Bragg's angle. From the X-ray line broadening, the crystallite size of the synthesized products is estimated around $17 \mathrm{~nm}(r= \pm 10 \%)$.

\section{Particles morphology (SEM and AFM measurements)}

The SEM image clearly indicates the shape and morphology of AgNPs. From the image (Fig. 5a, b), AgNPs are found in cubic shape with scattered particle due to the electrostatistic reflection. EDS analysis was confirmed the chemical composition of AgNPs with higher accumulation of $\mathrm{Ag}$.

The surface morphology and size of the Ag nanoparticles harvested after $120 \mathrm{~h}$ of incubation were studied by AFM. The two- and three-dimensional images of the nanoparticles are shown in Fig. 6a, b. From the 2D view, well-separated spherical particles are seen. The sizes of the particles are in the range of 2-55.8 $\mathrm{nm}$. However, most of the particles were in the range of $12 \mathrm{~nm}$. The 3D view revealed that the growth direction of all the particles was almost same confirming the single crystalline nature of the cubic phase of $\mathrm{Ag}$ nanoparticles.

Photocatalytic degradation

Photocatalytic degradation of methyl orange dye was investigated using biometrically synthesized silver nanocatalysts by solar irradiation technique at different time intervals as shown in Fig. 7. The characteristic absorption peak of methyl orange solution was found to be $420 \mathrm{~nm}$. Degradation of methyl orange was visualized by decrease in peak intensity within $10 \mathrm{~h}$ of incubation time. There is no considerable shift in peak position for methyl orange solution without exposure to Ag nanocatalysts. Kansal et al. (2006) have reported that compared to other irradiation techniques, solar light was found to be faster in decolorizing methyl orange in the presence of metal catalyst. The adsorption of Ag nanoparticles on the methyl orange solution was initially low and further increased with constant increase in time. Altogether, the photocatalytic properties of $\mathrm{Ag}$ nanoparticles in visible light may be well due to excitation of SPR, which is nothing but oscillation of charge density that can propagate at the interface between metal and dielectric medium (Garcia 2012).

\section{Conclusion}

To conclude, this is an efficient, eco-friendly and simple process. The nanoparticles were found to be active in degrading methyl orange solution with visible light illumination. These findings suggest that silver nanoparticles synthesized by facile method from $H$. musciformis are able to degrade dyes in the presence of visible light and pave way for ecological health and environmental bioremediation. 
Acknowledgments The authors wish to thank Dr. K. Arumugam, Professor and Head, Department of Botany, Annamalai University, for providing necessary laboratory facilities to carry out this work. We also thank Dr. S. Bharathan, Professor and Head, Department of Physics. Authors cordially thank Dr. B. Shanthi and Dr. G. Sivakumar, CISL Lab, Department of Physics, Annamalai University, for their help to observed SEM and AFM, for his stimulating discussions during the performance of this work.

Open Access This article is distributed under the terms of the Creative Commons Attribution License which permits any use, distribution, and reproduction in any medium, provided the original author(s) and the source are credited.

\section{References}

Al-Warthan A, Kholoud MM, El-Nour A, Eftaiha A, Ammar RAA (2010) Synthesis and applications of silver nanoparticles. Arab J Chem 3:135-140

Chen H, Hao F, He R, Cui DX (2007) Chemiluminescence of luminol catalyzed by silver nanoparticles. $J$ Coll Interface Sci 315:158-163

Garcia MA (2012) Surface plasmons in metallic nanoparticles: fundamentals and applications. J Phys D Appl Phys 44:28

Gurunathan S, Kalishwaralal K, Vaidyanathan R, Venkataraman D, Pandian SRK, Muniyandi J, Hariharan N, Eorn SH (2009) Biosynthesis, purification and characterization of silver nanoparticles using Escherichia coli. Coll Surf B Biointerfaces 74:328-335

Jain P, Pradeep T (2005) Potential of silver nanoparticle-coated polyurethane foam as an antibacterial water filter. Biotechnol Bioeng 90:59-63

Kannan RRR, Stirk WA, Van Staden J (2013) Synthesis of silver nanoparticles using the seaweed Codium capitatum P.C. Silva (Chlorophyceae). S Afr J Bot 86:1-4

Kansal SK, Singh M, Sudo D (2006) "Studies on $\mathrm{TiO}_{2} / \mathrm{ZnO}$ photocatalysed degradation of lignin. J Hazard 153:412-417

Kathiresan K, Asmathunisha N (2013) A review on biosynthesis of nanoparticles by marine organisms. Coll Surf B 103:283-287
Kumar P, Senthamil Selvi S, Lakshmi Praba A, Prem Kumar K, Ganeshkumar RS, Govindaraju M (2012a) Synthesis of silver nanoparticles from Sargassum tenerrimum and screening phytochemcials for its anti-bacterial activity. Nano. Biomed Eng 4:12-16

Kumar P, Senthamilselvi S, Govindaraju M (2012b) Seaweedmediated biosynthesis of silver nanoparticles using Gracilaria corticata for its antifungal activity against Candida spp. Appl Nanosci. doi:10.1007/s13204-012-0151-3

Kumar A, Choudhary P, Verma P (2011) A comparative study on the treatment methods of textile dye effluents. Global J Environ Res 5:46-52

Mohamed RM, Mkhalid IA, Baeissa ES, Al-Rayyani MA (2012) Photocatalytic degradation of methylene blue by $\mathrm{Fe} / \mathrm{ZnO} / \mathrm{SiO}_{2}$ nanoparticles under visible light. J Nanotechnol. doi:10.1155/ 2012/329082

Murphy CJ (2008) Sustainability as a design criterion in nanoparticle synthesis and applications. J Mater Chem 18:2173-2176

Rai G, Vyjayanti VN, Dorjsuren D, Simeonov A, Jadhav A, Wilson DM, Maloney DJ (2012) Synthesis, biological evaluation and structure-activity relationships of a novel class of apurinic/ apyrimidinic endonuclease 1 inhibitors. J Med Chem 55(7):3101-3112

Rashed MN, El-Amin AA (2007) Photocatalytic degradation of methyl orange in aqueous $\mathrm{TiO}_{2}$ under different solar irradiation sources. Int J Phys Sci 2:73-81

Satyavani K, Gurudeeban S, Ramanathan T, Balasubramanian T (2011) Biomedical potential of silver nanoparticles synthesized from calli cells of Citrullus colocynthis (L.). J Nanobiotechnol 9:43-50

Wang G, Liao C, Wu F (2000) Photodegradation of humic acids in the presence of hydrogen peroxide. Chemosphere 42:379-387

Wang P, Huang B, Qin X, Zhang X, Dai Y, Wei J, Whangbo MH (2008) Efficient and stable photocatalyst under visible light. Chem Eur J 14:10543-10546

Williams D (2008) The relationship between biomaterials and nanotechnology. Biomaterials 29:1737

Yang JI, Yeh CC, Lee JC, Yi SC, Huang HW, Tseng CN, Chang HW (2012) Aqueous extract of the edible Gracilaria tenuistipitata are protective against $\mathrm{H}_{2} \mathrm{O}_{2}$-induced DNA damage, growth inhibition, and cell cycle arrest. Molecules 17:7241-7254 